\title{
O dicionário como antologia lírica, romance, autobiografia
}

The dictionary as lyrical anthology, novel, autobiography

\section{Helena Martins}

Pontifícia Universidade Católica do Rio de Janeiro, Rio de Janeiro, RJ, Brasil

Resumo: Este artigo reflete sobre um depoimento de Guimarães Rosa, no qual o escritor, contrariando a imagem típica do dicionário como testemunho de um sistema objetivo de representação, caracteriza-o, de forma alternativa e paradoxal, como a um só tempo antologia lírica, romance e autobiografia. Toma-se tal depoimento como metonímia de um pensamento sofisticado e relevante sobre a linguagem e discute-se a pertinência de lhe dar lugar em uma História das Ideias Linguísticas.

Palavras-chave: História das Ideias Linguísticas. Dicionários. Guimarães Rosa. Arte e pensamento.

Abstract: This paper reflects on a statement once made by Guimarães Rosa regarding dictionaries: subverting the typical image of the dictionary as evidence of an objective system of representation, the author presents it, paradoxically, as at once lyrical anthology, novel and autobiography. This statement is taken here as a metonymy of a sophisticated and relevant metalinguistic thought, and the pertinence of placing it within a History of Linguistic Ideas is discussed.

Keywords: History of Linguistic Ideas. Dictionaries. Guimarães Rosa. Art and thought. 
Este texto constela em torno de uma fala de Guimarães Rosa, um pequeno trecho da conhecida entrevista que ele deu ao crítico alemão Günter Lorenz, durante um congresso de escritores latino-americanos, em Gênova, no ano de 1965. A passagem é a seguinte:

Hoje, um dicionário é ao mesmo tempo a melhor antologia lírica. Cada palavra é, segundo sua essência, um poema. Pense só em sua gênese. No dia em que completar cem anos, publicarei um livro, meu romance mais importante: um dicionário. Talvez um pouco antes. E este fará as vezes

Helena Martins de minha autobiografia. (ROSA; LORENZ, 2009, p. lxvii, grifos nossos¹).

O dicionário como antologia lírica, romance, autobiografia: no espaço curto de cinco linhas, o dicionário tem a sua compreensão convencional triplamente subvertida. Como pensar um dicionário como antologia lírica? Como romance? Como autobiografia? E mais: como pensar a deriva entre essas três diferentes possibilidades, ou ênfases, que Rosa faz conviver paradoxalmente no fôlego de umas poucas frases?

Gostaria de explorar aqui a hipótese de que esse depoimento pode funcionar como metonímia de um pensamento relevante sobre a linguagem - um pensamento relevante o bastante para merecer talvez lugar em uma História das Ideias Linguísticas.

Se o propósito é refletir sobre a força investigativa do pensamento de um escritor, convém começar pelo plano mais geral, dizendo algumas palavras sobre o modo como tomo aqui a relação entre arte $\mathrm{e}$ pensamento, e mais especificamente a relação entre literatura e pensamento linguístico. Um episódio conhecido, envolvendo os conterrâneos Roman Jakobson e Vladimir Nabokov, dá-me a oportunidade de caracterizar por contraste e de forma abreviada a minha própria perspectiva.

Sabe-se que, em 1957, Nabokov se candidatou a um cargo de professor de literatura russa no Departamento de Línguas e Literaturas Eslavas da Universidade de Harvard. Consultado sobre a candidatura do escritor, Jakobson, que na época tinha uma cátedra naquela universidade, teria dito: "Senhores, respeito o talento literário do senhor Nabokov, mas a quem passaria pela cabeça convidar um elefante para ministrar aulas de zoologia?" (ALEXANDROV, 1995, p. xlv)². A pergunta

"Diálogo com Guimarães Rosa", doravante DGR.

São minhas todas as traduções de textos aqui citados. 
retórica de Jakobson dá testemunho da posição que é precisamente oposta àquela assumida aqui: segundo o que se insinua nessa pergunta, a literatura, na condição de manifestação artística de linguagem, é sempre objeto e nunca sujeito de conhecimento acadêmico: pedir ao escritor que ensine literatura seria algo análogo a pedir a um elefante para ensinar zoologia - aos elefantes, diria Jakobson, nada podemos perguntar; precisamos, muito ao contrário, explicá-los.

A pergunta de Jakobson respira, claro, a atmosfera estruturalista e formalista do tempo, um ideário que já então convivia com uma apreciável dissidência. Sabemos que a perspectiva insinuada nessa pergunta é contemporânea de outros modos de ver a relação entre arte e pensamento. Sabemos, na verdade, que formas alternativas de ver essa relação são bem mais antigas: nada de muito novo, afinal, na percepção

O dicionário como antologia lírica, romance, autobiografia de que a literatura sabe algo. Que as virtudes da literatura excedem, por exemplo, as funções mimética e catártica que lhe tinham sido classicamente atribuídas por Aristóteles, disso já sabia o próprio Aristóteles, no século IV a.C. Nas páginas de sua Poética, ao lado da ênfase na definição da poesia trágica como ocasião terapêutica, como ocasião de purgar as emoções do terror e da piedade, encontramos a célebre afirmação da superioridade da Poesia em relação à História. Para lembrar: "não diferem o historiador e o poeta por escreverem verso ou prosa [...] diferem, sim, em que diz um as coisas que sucederam, e outro as que poderiam suceder" (Poética, IX, 1451a-b).

O próprio Jakobson, ao lado de seus colegas formalistas, reconheceu também, é claro, vigores especiais na literatura e na arte: se é verdade que Jakobson não viu em Nabokov a qualificação necessária para atuar na esfera teórica e acadêmica, também é verdade que insistiu sempre numa visão em que a literatura nada teria de inócua. Compreendida como violência organizada contra a fala comum, como ocasião de Ostranenie, a literatura seria, ao contrário, uma força importante de compreensão e de transformação. Mas interessava a Jakobson e aos formalistas, como interessou a Aristóteles, explicar teoricamente como é que a literatura realizaria as suas proezas; e confiavam, como confiou Aristóteles, que o projeto era viável. A confiança na viabilidade de uma ciência geral da literatura é irmã da confiança na viabilidade de uma ciência geral da linguagem, capaz de distinguir objetivamente as suas regiões, de estabelecer cientificamente, por exemplo, a diferença entre a linguagem comum e a linguagem poética. Tratava-se de compreender 
as regras da fala comum, regras contra as quais a literatura exerceria sua violência, ela mesma uma violência organizada, regrada, teorizável. Tratava-se de compreender, em suma, por um lado as regras e por outro as regras para quebrar as regras.

São bastante conhecidas as críticas e desconstruções das apostas estruturalistas e formalistas, tanto quanto aquelas dirigidas aos projetos essencialistas de uma maneira mais geral. Quando não podemos mais contar com grandes metateorias e discursos totalizantes, os saberes prometidos na literatura e nas artes, caracteristicamente fragmentários e Helena avessos à doutrina, revestem-se de um estatuto renovado, prometem Martins abrir futuros. A situação é paradoxal: por um lado, desconstroem-se sistematicamente as possibilidades de uma demarcação objetiva, descontextualizada e essencializante entre as esferas do literário e do não literário. Por outro, a literatura, percebida como uma estranha instituição, como disse certa vez Derrida, permanece alvo de formidável interesse:

\footnotetext{
A literatura é a coisa mais interessante do mundo, talvez mais interessante que o mundo; e é por isso que, ainda que ela não tenha definição, aquilo que se anuncia e que se recusa sob o nome de literatura não pode ser identificado com qualquer outro discurso. Jamais será científica, filosófica, conversacional. (DERRIDA, 1992, p. 42).
}

Qualquer que seja o caso, a muitos dos pensadores que de alguma forma se afinam com essa percepção de Derrida, deixa de parecer descabido, por assim dizer, fazer perguntas ao elefante - passa a haver interesse em interrogar a literatura (e mesmo de alguma forma praticá-la) em vez de (apenas) buscar explicá-la. Sabemos que são muitos e muito diversos os nomes evocáveis aqui: Foucault, Lacan, e antes dele Freud, Heidegger, e antes dele Nietzsche, Wittgenstein, Deleuze, Blanchot, e assim por diante.

Interessa particularmente aqui, como já dissemos, interrogar a literatura sobre como pensa particularmente a linguagem - flagrar ali o gesto metalinguístico. Entre os que excluíram de suas aspirações o ideal de uma metalinguagem universal, há os que se interessam ainda pela história descontínua e não teleológica das práticas metalinguísticas. É o caso exemplar dos projetos de pesquisa capitaneados ou inspirados por Sylvain Auroux (1992, p. 13): “seja a linguagem humana, tal como ela se 
realizou na diversidade das línguas; saberes se constituíram a seu respeito; este é o nosso objeto". A pergunta geral é aqui: como compreender os saberes metalinguísticos que se oferecem no espaço institucional da literatura?

No campo da História das Ideias Linguísticas, parece-me, o interesse pelo espaço da literatura tem se voltado principalmente para os processos de "constituição/preservação de um corpus literário", tomado como elemento importante na difusão e na cristalização dos saberes linguísticos, o foco recaindo com frequência sobre as relações entre “a literarização dos idiomas e a identidade nacional" (AUROUX, 1992, p. 28-29). No entanto, um fenômeno que tem merecido relativamente pouca atenção na esfera desse programa de pesquisa são estes que aqui denomino provisoriamente como gestos metalinguísticos literários -

O dicionário como antologia lírica, romance, autobiografia gestos, diga-se, endêmicos na literatura produzida, desde o século XX, sob o signo da assim chamada crise da linguagem, crise manifesta, de uma forma ou de outra, nos (pós-)modernismos de quase todas as persuasões (SHEPPARD, 1991).

Um sintoma trivial mas eloquente de que a temática da linguagem e do sentido é mobilizada com especial recorrência no espaço da literatura recente é, por exemplo, a frequência com que textos teórico-descritivos e históricos sobre a linguagem são epigrafados com passagens literárias: logo ali abaixo do título, flagramos a toda hora um Lewis Carroll, uma Clarice Lispector, um Fernando Pessoa, um Guimarães Rosa, um Rimbaud, para citar apenas um punhado de nomes. Se pudermos reconhecer, em muitas dessas epígrafes, verdadeiros gestos metalinguísticos, é de se perguntar por que não deveriam, por assim dizer, escorrer para o corpo do texto - nos termos aqui enfocados, por que não deveriam ser elas mesmas tomadas como instâncias dignas de figurar numa história dos saberes linguísticos.

É oportuno indicar parenteticamente o que estou tomando, de forma abrangente, como gesto metalinguístico no espaço institucional da literatura: acomodam-se desde glossários apensos por escritores a seus textos, passando por tematizações explícitas sobre questões da linguagem - como quando o Riobaldo de Guimarães Rosa diz, depois de saber que Reinaldo se chama de fato Diadorim, "Era um nome, ver o quê. Que é que é um nome? Nome não dá: nome recebe" (p. 62) - e também, claro, os abalos e esgarçamentos de ordens linguísticas cristalizadas que, característicos das literaturas de todos os tempos, pensam 
a linguagem na medida em que dão a ver, como disse certa vez Maurice Blanchot, "tudo o que uma língua contém de futuro num momento particular, tudo o que nela convoca ou indica um estado que é outro, por vezes perigosamente outro" (BLANCHOT, 1971, p. 71). Incluem-se, por fim, entre os gestos metalinguísticos de nosso interesse, depoimentos, ensaios, entrevistas, nos quais escritores e poetas exprimem suas concepções sobre a linguagem - como é o caso do objeto deste texto.

Retomando a questão: se deixamos de fora do projeto de uma História das Ideias Linguísticas tais gestos metalinguísticos literários, Helena não estaremos talvez incorrendo naquele equívoco de que falou certa Martins vez Michel Pêcheux (1997, p. 53), o equívoco de considerar a literatura como uma espécie de "domingo do pensamento"? Determinada a esquivar-me do equívoco, volto agora à fala desconcertante de Rosa sobre os dicionários, procurando aferir a sua relevância.

Como já vimos, é uma fala que de fato desconcerta a compreensão de senso comum do dicionário de três maneiras diferentes (e, o que é mais surpreendente, de três maneiras diferentes ao mesmo tempo). Parece, no entanto, desconcertar também, sem propriamente refutar, um importante pensamento sistemático contemporâneo acerca do estatuto dos dicionários no âmbito da História das Ideias Linguísticas, pensamento merecedor de ampla atenção acadêmica. Com o mesmo Sylvain Auroux de que agora falávamos, aprendemos que o dicionário é um advento que instrumenta e reifica a língua: o dicionário e a gramática constituiriam, com efeito, "as duas tecnologias que são ainda hoje os pilares de nossos saberes metalinguísticos" (AUROUX, 1992, p. 65). Parte crucial do processo de gramatização, o dicionário, longe de perfazer um depósito de alinhamentos objetivos entre significados e significantes, atua, sempre permeado de história, como um instrumento de homogeneização linguística, como instrumento que - ainda que de forma cronicamente ineficaz - atua no sentido de reduzir a dispersão fenomênica e a pluralidade das práticas verbais. Sob esse ângulo, o dicionário funcionaria como um artefato vocacionado a nos convencer de que, como diria Foucault, "uma providência pré-discursiva" e "uma cumplicidade com o mundo" dispõem a palavra a nosso favor, rarefazendo mal e mal o nosso 
descontínuo, de combativo, de desordem, também, e de perigoso, desse grande zumbido incessante e desordenado que é o discurso (FOUCAULT, 1996, p. 50).

Rosa é um inimigo declarado desses mecanismos de rarefação: voltando-se sempre para "o remoto e o estranho" (DGR, p. xxxiv), acredita que o escritor é alguém que deve "se sentir à vontade no incompreensível” (DGR, p. lvii) - e está inteiramente atento a essas forças de homogeneização e rarefação dos dicionários e das gramáticas. A certa altura da entrevista, ele nos diz:

[M] eus livros [são] escritos em um idioma próprio, meu, e pode-se deduzir daí que não me submeto à tirania da gramática e dos dicionários dos outros. A gramática e a chamada filologia, ciência linguística, foram inventadas pelos inimigos da poesia. (DGR, p. xxxix).

As passagens que citei da entrevista até agora já instanciam o que parece ser o movimento predominante na conversa que Rosa trava com o alemão: o movimento do paradoxo. 0 dicionário é um tirano e um inimigo da poesia, mas é também uma antologia lírica, um romance, uma autobiografia. Rosa em um momento escreve num idioma próprio, para logo adiante contradizer-se: "[o]lhe, não entendo por que se faz tanto barulho pelo que deram de chamar 'a língua Guimarães Rosa'..." (DGR, p. xlviii). A esse mesmo movimento - o de fazer afirmações para em seguida cancelá-las ou deformá-las - recorre quando Lorenz pergunta a Rosa sobre literatura e política, sobre o papel da crítica, sobre sua poética, sobre a brasilidade, e assim por diante. Rosa parece comprazer-se em escapulir a todas as generalizações que o entrevistador a custo vai tentando fazer. Em certos momentos, parece mesmo se aborrecer: "Estou adivinhando seu pensamento! Agora, além de tudo, quer me exigir um credo." (DGR, p. xli). Seja como for, as esquivas de Rosa dão menos testemunho de irritação e impaciência do que de um interesse genuíno pelo que se poderia descrever como uma produtividade do paradoxo, por uma atenção ininterrupta pelo que não se deixa reduzir, pelo que não se pacifica.

Quando, no início da entrevista, Lorenz busca obter informações sobre a formação do escritor remetendo a aspectos de sua biografia (chama a atenção para o fato de que ele foi médico, rebelde, soldado), Rosa não se furta a reconhecer a importância dessas experiências: 
“[c]omo médico conheci o valor místico do sofrimento; como rebelde, o valor da consciência; como soldado, o valor da proximidade da morte" (DGR, p. xxxv). Lorenz então se apressa em perguntar se essas vivências não constituiriam a espinha dorsal de Grande Sertão: veredas. Rosa concede que elas formaram seu "mundo interior", mas se vê compelido a ressalvar: "para que isto não pareça demasiadamente simples, queria acrescentar que também configuram meu mundo a diplomacia, o trato com cavalos, vacas, religiões e idiomas" (DGR, p. xxxvi). Desconcertado com essa resposta, Lorenz retruca: "[p]arece uma sucessão e uma comHelena binação um tanto curiosa de motivos" - ao que Rosa responde: "[b]em, Martins tudo isto é curioso, mas o que não é curioso na vida? Não devemos examinar a vida do mesmo modo que um colecionador de insetos contempla os seus escaravelhos" (DGR, p. xxxvi). Nesse e em muitos outros casos, Rosa dá a ver, enfim, o desejo não apenas de reconhecer, mas também de habitar os paradoxos:

a vida, a morte, tudo é, no fundo, paradoxo. Os paradoxos existem para que ainda se possa exprimir algo para o qual não existem palavras. Por isso acho que um paradoxo bem formulado é mais importante que toda a matemática, pois ela própria é um paradoxo, porque cada fórmula que o homem pode empregar é um paradoxo (DGR, p. xxxvi).

Podemos, então, entrever na produtividade da experiência paradoxal um primeiro traço importante da reflexão de Rosa acerca dos dicionários: vejo ganho em pensar o dicionário como a um só tempo inimigo da poesia e repositório de poesia, a só um tempo gênero lírico, gênero romanesco e gênero autobiográfico; a um só tempo um livro meu, por escrever, e um livro dos outros, sempre já lá, sempre já escrevendo por mim. Apontando essa caracterização inquieta, sem de modo algum desejar aquietá-la, uso o espaço que me resta aqui para, de maneira apenas sugestiva, dizer algumas palavras acerca dessas três ênfases paradoxalmente colaboráveis com que Rosa pensa o dicionário.

Começo pelo fim, pela parte que me parece mais enigmática: o dicionário como autobiografia. A pergunta que Lorenz faz a Rosa logo depois da passagem com que abri este texto é a seguinte:

Estou pensando em como classificar esta declaração sobre o dicionário. Pertence ao capítulo de seu gosto pelos paradoxos, ou deve ser 
interpretada literalmente? Não poderia ser entendida de forma absolutamente literal, pois um dicionário é o mais impessoal de todos os livros, e você, como já me havia dito, é inimigo das intimidades literárias. (DGR, p. lvii).

Rosa responde:

O dicionário

como

Um dicionário não é tão completamente impessoal como você pensa; antologia por isso falei dele relacionado à minha autobiografia. Pode entender literalmente o que acabo de lhe dizer e acrescentá-lo à minha poética. A lírica, romance, personalidade do escritor, ao escrever, é sempre seu maior obstáculo. (DGR, p. lvii). autobiografia

Ao dizer que a personalidade do escritor é seu maior obstáculo, Rosa se aproxima das célebres palavras de Barthes, quando, em seu clássico, "A morte do autor", fala-nos da

\footnotetext{
necessidade de pôr a própria linguagem no lugar daquele que até então se supunha ser o seu proprietário; [...] para nós, é a linguagem que fala, não é o autor; escrever é, através de uma impessoalidade prévia [...] atingir aquele ponto em que só a linguagem atua, ‘performa', e não 'eu’ [...] (BARTHES, 2004, p. 59).
}

Claro está que, depois de Barthes e de tantos outros que de alguma forma pensaram como ele, não podemos mais compreender a autoria de um romance, um poema ou um conto, por exemplo, como operador de identidades pessoais estáveis, marca de gênio ou coisa que o valha - nesse contexto, a autobiografia é agora amiúde tomada como autoficção. Claro está também que autores como Barthes, Foucault e outros que escreveram textos seminais sobre autoria deixaram-nos com uma série de assuntos pendentes, dando ensejo a variados movimentos de retomada crítica, mais ou menos acomodáveis sob a expressão "retorno do autor", expressão que, ela mesma, já dá também sinais de algum cansaço (KLINGER, 2008). Como convocar para a esfera desta discussão a fala de Rosa, fala dita tão de passagem, em uma entrevista no ano de 1965 ?

o que me parece mais interessante aqui é a instrutiva volatilidade da conexão dicionário-autobiografia. Ao afirmar simultaneamente que 
Helena

Martins

o dicionário não é tão impessoal como se pensa e que a personalidade daquele que escreve - e daquele que escreve uma autobiografia, um dicionário - é o seu maior obstáculo, Rosa põe em estado periclitante a oposição mais ou menos trivial entre livro pessoal e livro impessoal que parece estar pressuposta na pergunta de Lorenz. No entanto, mais que isso, sem deixar de esvaziar o ato da escrita da inflação autoral subjetiva que tantos tantas vezes já criticaram, detém também talvez uma confiança precipitada no êxito da empreitada de "atingir aquele ponto em que só a linguagem atua, 'performa', e não 'eu”', de que falava Barthes.

$\mathrm{O}$ dicionário, livro que, qualquer que seja a teoria de nossa preferência, figura historicamente, em nossas tribos ocidentais, como aquele que promete dar testemunho da língua de todos, é, para Rosa, um livro, em algum sentido, pessoal. Não creio que estivesse enfatizando (apenas) a subjetividade dos autores mais ou menos anônimos que escrevem os verbetes. Parece-me mais fértil pensar que ele aponta o paradoxo pelo qual a língua é, em certo sentido, sempre inteiramente dos outros e sempre inteiramente nossa. A fala perplexa do personagem inominável de Samuel Beckett nos ajuda aqui: "sou de palavras, sou feito de palavras, das palavras dos outros, que outros..." (BECKETT, 2002, p. 148, grifo nosso).

Escrever um dicionário como autobiografia seria talvez inscrever-se nele, na língua de todos, de diferentes maneiras e continuamente, sem ponto de partida, sem ponto de parada. A contaminação recíproca e impacificável entre o dicionário e a autobiografia fala talvez de uma subjetividade enlaçada na linguagem, esta tomada não como hipóstase, mas como forma de vida. Seria enfim uma subjetividade que alcançaria o dicionário quando nele se pudesse acomodar a ocasião em que, nas palavras aptas de Giorgio Agamben (2007, p. 57), "o ser vivo, ao encontrar a linguagem e pondo-se nela em jogo sem reservas, exibe em um gesto a própria irredutibilidade a ela".

E o que dizer agora do dicionário como antologia lírica? Fica claro que essa é uma imagem que subverte de modo igualmente óbvio a ideia comum do dicionário como um compêndio que registraria de forma objetiva um sistema racional de representação homogêneo e compartilhado. Já vimos que o dicionário mais forja do que representa a experiência do homogêneo e do sistemático - e podemos acrescentar aí a ideia, cara a tantos de nós hoje, de que a forja é, no caso, sempre histórica e ideológica. Mas as ênfases de Rosa parecem ser outras, quando ele afirma que cada palavra é em essência um poema. 
Ele remete aqui, creio, a uma certa possibilidade que o dicionário teria de estranhar-se a si mesmo, de conjurar seu próprio futuro, de desparafusar-se, por assim dizer. Se insiste que "a poesia se origina da modificação de realidades linguísticas" (DGR, p. lx), ao afirmar o dicionário como antologia lírica, reconhece, ali mesmo onde as realidades linguísticas mais se cristalizam, a abertura para o seu modificar-se, para o seu devir. E isso em muitos planos. Um deles: cada palavra no dicionário é, tipicamente, apresentada como uma lista de sentidos e informações gramaticais, lista em geral hierarquizada com rubricas que informam coisas do tipo: etimologicamente, por extensão, figurativamente; tupi, anglicismo, galicismo; regional, popular, formal; antropologia, filosofia, medicina, música etc. Mas o que nos impede de desparafusar essas hierarquias, de aproveitar as surpresas que nos reservam os sentidos assim

O dicionário como antologia lírica, romance, autobiografia reunidos, seu testemunho do acaso? Por que não errar com a palavra entre o que se diz literal e o que se diz figurativo, entre o regional e o nacional, entre o diacrônico e o sincrônico, entre o erudito e o popular, entre o português, o tupi, o inglês, o francês; entre o cotidiano, o científico, o artístico; entre o verbo, o adjetivo, o substantivo, e assim por diante? o que Rosa parece fazer é, entre outras coisas, convidar-nos a esperar de cada palavra no dicionário, em sua sonoridade e em sua constelação de sentidos, menos um inventário ou catálogo semânticogramatical bem comportado, e mais um sinal de sua vital irredutibilidade e indeterminação: a pesquisa nos dicionários, que, sabe-se, marcou o ofício de Rosa como escritor, terá de ter tido a ver com seu declarado compromisso: "como escritor, devo me prestar contas de cada palavra e considerar cada palavra o tempo necessário até ela ser novamente vida" (DGR, p. lx).

Vistas como poemas, enfim, as palavras perdem em determinação - o que, no caso de Rosa, equivale a dizer que ganham em indeterminação. No entanto, habitando mais uma vez a produtividade do paradoxo, Rosa vê nessa indeterminação uma espécie de exatidão: “a poesia”, ele nos diz, "é também uma irmã tão incompreensível da magia", acrescentando que se trata de uma "álgebra mágica" - mágica "porque é mais indeterminada e portanto mais exata" (DGR, p. lviii). A palavra-poema do dicionário de Rosa é talvez mais ideograma que palavra fonética - como ensina Haroldo de Campos (1977, p. 56), "um ideograma isolado pode ser, em si próprio, pela alta voltagem obtida com a justaposição direta dos elementos, um verdadeiro poema completo". Seja como for, Rosa dá 
a ver, no próprio interior do dicionário - lugar privilegiado da rarefação dos acasos e das indeterminações -, a possibilidade do indeterminado, de liberarem-se fluxos de vida. Algo nessa direção transparece na descrição que ele faz de seu "método":

Também aqui pode-se determinar meu ponto de partida, que é muito simples. Meu lema é: a linguagem e a vida são uma coisa só. Quem não fizer do idioma o espelho de sua personalidade não vive; e como a vida é uma corrente contínua, a linguagem também deve evoluir constante-

Helena Martins mente. [...] O idioma é a única porta para o infinito, mas infelizmente está oculto sob montanhas de cinzas. Daí resulta que tenha de limpá-lo, e como é a expressão da vida, sou eu o responsável por ele, pelo que devo constantemente umsorgen [...] O bem-estar do homem depende do descobrimento do soro contra a varíola e as picadas de cobras, mas também depende de que ele devolva à palavra seu sentido original. (DGR, p. lx).

Devolver a palavra a seu sentido original seria restituí-la, de algum modo, ao seu estado de poema, soprar a montanha de cinzas que o recobre. Novamente o paradoxo: a origem liga-se ao infinito, voltar à origem é não ter origem, nem começo nem fim. Subverte-se assim inteiramente o que se compreende prosaicamente por ir ao dicionário na busca de sentidos originais.

Para terminar, o dicionário como romance. Também aqui poderíamos trazer de saída a questão da luta histórica, do jogo das forças ideológicas: pensar o dicionário como repositório de circunscrições e definições que fazem e refazem a história e a estória e que são ao mesmo tempo testemunho dos tempos. Mas também aqui, creio, são, ou prometem ser, distintas as ênfases de Rosa.

Comecemos por observar alguns escrúpulos de autor quanto à palavra "romance", para que não percamos de vista o modo singular como dela se apropria ao associá-la à palavra "dicionário". Não à toa, Rosa declara, em certo momento da entrevista, a sua admiração pela nivola - a conhecida invenção de Unamuno, escritor e filósofo que, segundo o próprio Rosa, "poderia ter sido [s]eu avô" (DGR, p. xxxvii). Sabe-se que, objetando ao conceito usual de novela (em português, romance), Unamuno cunhou o neologismo anagramático nivola, com o qual qualificou a sua obra Niebla, desejando afastá-la dos princípios então dominantes do realismo (narração onisciente em terceira pessoa, 
ambientação realista etc.). Igualmente avesso a tais imperativos, Rosa chega a recusar que a categoria romance pudesse ser aplicada ao seu trabalho em qualquer sentido:

Não, não sou romancista; sou um contista de contos críticos. Meus romances e ciclos de romances são na realidade contos nos quais se unem a ficção poética e a realidade. Sei que daí pode facilmente nascer um filho ilegítimo, mas justamente o autor deve ter um aparelho de controle: sua cabeça. Escrevo, e creio que este é o meu aparelho de controle: o idioma português, tal como o usamos no Brasil; entretanto, no fundo, enquanto vou escrevendo, eu traduzo, extraio de muitos outros idiomas. (DGR, p. xxxix).

O dicionário como antologia lírica, romance, autobiografia

O interessante é que, ao afirmar que escreve "contos críticos" que unem "ficção poética e realidade", Rosa se afasta do romance realista clássico, sem contudo abrir mão do desejo de endereçar criticamente a realidade - ainda que reconhecendo os riscos de gerar, a partir de sua união com a ficção poética, "um filho ilegítimo". E, ao falar do "aparelho de controle" que protegeria o escritor de tais riscos, caracteriza-o como "sua cabeça", para logo em seguida apresentá-lo como "o idioma", o idioma nativo, mas também as traduções de muitos outros idiomas. A cabeça do escritor, o(s) seu(s) idioma(s): novamente aqui se flagra a reciprocidade inquieta entre o privado e o público, o dentro e o fora, o eu e os outros.

Importa observar, além disso, o modo como Rosa aplaude ou critica os romancistas de que vai falando, o que nos dá ainda mais repertório com que pensar a relação do romance com o dicionário:

Goethe nasceu no sertão, assim como Dostoievski, Tolstoi, Flaubert, Balzac; ele era [...] um homem que vivia com a língua e pensava no infinito. [...] Não escrevia para o dia, mas para o infinito. Era um sertanejo. Zola, para tomar arbitrariamente um exemplo contrário, provinha apenas de São Paulo. (DGR, p. liii).

Ao prometer, com humor, que aos cem anos escreveria um dicionário, "o seu romance mais importante", Rosa haveria de aspirar ao sertão, não a São Paulo. A debilidade que reconhecia nos romances de Zola, em quem “a consciência está desperta, mas falta o vigor da 
língua" (DGR, p. liv), contrastaria com a força dos escritos daqueles que admirava, os que viviam com a língua e pensavam no infinito.

Conceber, com Rosa, o dicionário como um romance parece, então, pensá-lo como de alguma forma ligado a uma dimensão infralógica e refratária à consciência, infensa ao "bruxulear presunçoso da inteligência reflexiva, da razão, da megera cartesiana", como ele mesmo teria dito certa vez a seu tradutor italiano (BIZZARRI; ROSA, 2003, p. 91). Se tomamos o aparentemente neutro inventário alfabético de palavras como uma narrativa, será talvez uma narrativa oblíqua e fragmentária, Helena mais conto crítico que romance clássico, estória que dá a ver - ou faz Martins "sentir-pensar" (DGR, p. lix) - o estranho, o que não se reduz, nem se pacifica, nem se deixa explicar: “[c]omo romancista tento o impossível. Gostaria de ser objetivo, e ao mesmo tempo me olhar a mim mesmo com olhos de estranhos. Não sei se isso é possível, mas odeio a intimidade" (DGR, p. xlv).

Ainda mais uma vez, o paradoxo: o (impossível) desejo de ser objetivo estranhando-se. Talvez Rosa esteja aqui convidando-nos a pensar que formas de vida e de linguagem, desprovidas de qualquer lastro fixo e atemporal, são no entanto informadas por protoimagens em que se amalgamam, de modo a um só tempo contingente e coercitivo, certezas não cognitivas, refratárias à intelecção, estórias às quais aderimos sem compreender, convicções subterrâneas e silenciosas que, não configurando visões de mundo ou ideologias nomeáveis, descritíveis, só nos são franqueadas quando podemos realizar o impossível: a um só tempo viver com a língua e pensar no infinito. Se um dicionário poderia ser "o romance mais importante", é porque "meditando sobre as palavras", sem buscar nelas qualquer princípio racional transcendente, "o homem descobre a si mesmo" - a essa descoberta, Rosa articulou, não sem provocar um sem-número de incompreensões e acusações, a experiência de sentir-pensar a "metafísica da língua" (DGR, p. lii).

Essas descobertas e experiências "metafísicas" pouco ou nada têm a ver com o desvelamento intelectual de qualquer essência fixa e imutável. Arrancando, não sem humor, a palavra "metafísica" de seu conforto histórico antropocêntrico, Rosa afirma, por exemplo, que "o crocodilo vem ao mundo como um magister da metafísica, pois para ele cada rio é um oceano, um mar da sabedoria, mesmo que chegue a ter cem anos de idade" (DGR, p. xli). O crocodilo jamais dá ou deseja dar o rio por explicado, sendo nisso superior a sua metafísica. 
Outra indicação de que a expressão "metafísica da língua" tem em Rosa algo a ver com certa espécie historicamente anômala de universal - um universal que paradoxalmente não precede os particulares - é sua convicção de que "a língua dá ao escritor a possibilidade de servir a Deus corrigindo-o" (DGR, p. lii). o que é, entre nós, sejamos crentes ou ateus, uma figura suprema do universal imutável, de uma força invisível a responder por todas as nossas partições - ontológicas, estéticas, psicológicas, éticas e assim por diante -, liga-se agora ao idioma, e, mais importante, nele se deixa corrigir.

O dicionário, assim concebido, participaria de uma "literatura ilógica", capaz de transformar "o cosmo num sertão no qual a única realidade seja o inacreditável" (DGR, p. 1xi). Seria talvez ocasião de estranharmo-nos com objetividade.

o dicionário como antologia lírica, romance, autobiografia

Pensar o dicionário como autobiografia, como antologia lírica, como romance. Em todos os casos, estamos diante de uma reflexão sobre a linguagem que é ao mesmo tempo um convite para experimentá-la (sentir-pensar) de outra forma - e não apenas para compreendê-la de uma outra forma. Em todos os casos, creio, há promessa de movimento. Uma conhecida passagem de outra escritora afeita à produtividade dos paradoxos, Clarice Lispector, parece-me oportuna para fechar o texto e descrever essa promessa:

Perdi alguma coisa que me era essencial, e que já não me é mais. Não me é necessária, assim como se eu tivesse perdido uma terceira perna que até então me impossibilitava de andar mas que fazia de mim um tripé estável. Essa terceira perna eu perdi. E voltei a ser uma pessoa que nunca fui. Voltei a ter o que nunca tive: apenas as duas pernas. Sei que somente com duas pernas é que posso caminhar. Mas a ausência inútil da terceira me faz falta e me assusta, era ela que fazia de mim uma coisa encontrável por mim mesma, e sem sequer precisar me procurar. (LISPECTOR, 1998, p. 11).

O dicionário, com todas as suas promessas de fixidez e homogeneidade, foi amiúde pensado como uma "terceira perna" - mais ou menos eficaz. A originalidade de Rosa, que deveria lhe garantir talvez um lugar em uma História das Ideias Linguísticas, está em pensá-lo ao mesmo tempo como um instrumento para perdê-la. 


\section{Referências}

AGAMBEN, Giorgio. Profanações. Trad. de Selvino José Assmann. São Paulo: Boitempo, 2007.

ALEXANDROV, Vladmir E. (Ed.). The Garland companion to Vladimir Nabokov. New York: Garland Publishing, 1995.

ARISTÓTELES. Poética. Trad. de Eudoro de Souza. São Paulo: Nova Helena Cultural, 1987. (Os Pensadores).

Martins

AUROUX, Sylvain. A revolução tecnológica da gramatização. Trad. de Eni Orlandi. Campinas: Ed. da Unicamp, 1992.

BARTHES, Roland. A morte do autor. In: . 0 rumor da língua. Trad. de Mário Laranjeira. São Paulo: Martins Fontes, 2004. p. 57-64.

BECKETT, Samuel. o inominável. Trad. de Maria J. V. de Figueiredo. Lisboa: Assírio \& Alvim, 2002.

BIZZARRI, Edoardo; ROSA, João Guimarães. João Guimarães Rosa: correspondência com seu tradutor italiano. Rio de Janeiro: Nova Fronteira, 2003.

BLANCHOT, Maurice. L'amitié. Paris: Gallimard, 1971.

CAMPOS, Haroldo. A poética da brevidade. In: (Org.). A arte no horizonte do provável. São Paulo: Perspectiva, 1969. p. 53-90.

DERRIDA, Jacques. This strange institution called literature: an interview with Jacques Derrida. In: DEREK, Attrige (Ed.). Acts of literature. New York: Routlege, 1992. p. 33-75.

FOUCAULT, Michel. A ordem do discurso. Aula inaugural no Collège de France, pronunciada em 2 de dezembro de 1970. Trad. de Laura Fraga de A. Sampaio. São Paulo: Loyola, 1996. 
KLINGER, Diana. Escrita de si como performance. Revista Brasileira de Literatura Comparada, n. 12, p. 11-30, 2008.

LISPECTOR, Clarice. A paixão segundo G.H. Rio de Janeiro: Rocco, 1998.

PÊCHEUX, Michel. O discurso: estrutura ou acontecimento. 2. ed. O dicionário Trad. de Eni P. Orlandi. Campinas: Pontes, 1997.

como antologia lírica,

ROSA, João G.; LORENZ, Günter W. Diálogo com Guimarães Rosa. In: romance, COUTINHO, Eduardo (Org.). João Guimarães Rosa: ficção completa. autobiografia Rio de Janeiro: Nova Aguilar, [1965] 2009. v. 1. Grande sertão: Veredas. In: Coutinho, Eduardo (Org.). João Guimarães Rosa: ficção completa. Rio de Janeiro: Nova Aguilar, [1956] 2009. $2 \mathrm{v}$.

SHEPPARD, Richard. The crisis of language. In: BRADBURY, Malcolm; MCFARLANE, James (Ed.). Modernism: a guide to European Literature - 1890-1930. New York: Penguim, 1991. p. 323-336. 